\title{
The importance of Renal Anatomy in Endourologic Procedures
}

The March-April 2015 issue of the International Braz J Urol presents original contributions with a lot of interesting papers in different fields: Infertility, neuro-urology, BPH, Prostate Cancer, Renal Cancer, Tuberculosis, Genital trauma and basic research. The papers come from many different countries such as Brazil, USA, China, Turkey, Iran, Portugal, Egypt, Japan and Korea and as usual the editor's comment highlights some papers. We decided to comment 2 papers about Endourology.

Doctor Koyuncu and collegues, from Turkey performed on page 245 an interesting study about the treatment of lower pole stones. The authors compared the efficacy of intra-renal surgery and Percutaneous Nephrolithotomy (PNL) in lower pole stones $\geq 2$ $\mathrm{cm}$ in 109 patients retrospectively and they concluded that intra-renal surgery could be an effective treatment alternative to PNL in lower pole stones larger than $2 \mathrm{~cm}$, especially in selected patients. Further, multi-centric comparative studies with larger study population are needed to confirm these results.

Inferior pole stones can be treated with ESWL, flexible ureteroscopy and percutaneous nephrolitotripsy (1). Anatomical aspects of the inferior renal pole, especially calice distribution, angle between the lower infundibulum and renal pelvis (LIP), infundibular length and calice width, are determinant for the success of each treatment modality $(2,3)$. The size of calculi is one of most important factors for decision on the best treatment method (4). Stones wider than $20 \mathrm{~mm}$ are better treated with percutaneous surgery, while stones smaller than $10 \mathrm{~mm}$ show good results when treated by flexible ureteroscopy (FUR) or extracorporeal shockwave lithotripsy (ESWL), and stones between 10 and $20 \mathrm{~mm}$ are treated with FUR with good results (4). The spatial anatomy of the lower pole group of calices influences the success rate of FUR $(5,6)$. Patients with unfavorable parameters show lower stone free rates when FUR was the method of choice (5, 6). In this paper the authors analyzed only the size of the stones and do not analyzed the anatomic factors of the lower pole, one of the most important factors to decide the treatment in this kind of cases.

Doctor Balasar and collegues from Turkey performed on page 274 an interesting study about Incidence of retro-renal colon during percutaneous nephrolithotomy. They studied the number of retro-renal colon presence in the CT images taken before PNL applications in 394 patients retrospectively. The authors found that 27 patients (6.9\%) had retro-renal colon with $18(4.6 \%)$ on the left and $4(1.0 \%)$ on the right side. The other $5(1.3 \%)$ patients had bilateral retro-renal colons and concluded that retro-renal colon is more frequently found on the left side and on the lower pole of the kidney. Therefore, when accessing the lower pole of the kidney, especially on the left side, the risk of colonic injuries should be considered during PNL. 


\section{EDITORIAL}

The knowledge of kidney and retroperitoneum anatomy is very important to make the PNL. The procedure could be performed in prone or supine position and one of the most terrible complication of this procedure is the colon perforation. In a very recent and important radiologic paper (7) performed in 700 patients (350 made CT in prone position and 350 in supine position) the authors observed that $6.8 \%$ of patients in prone position had retro-renal colon and $2 \%$ of patients in supine position had retro-renal colon.

With the study of these 2 important papers we concluded that kidney and intra-renal anatomy are very important for all kind of endourologic procedures.

\section{REFERENCES}

1. Preminger GM: Management of lower pole renal calculi: shock wave lithothripsy versus percutaneous nephrolithotomy versus flexible ureteroscopy. Urol Res 2006;34(23):108-11.

2. Kumar PVS, Joshi HB, Keeley FX, Timoney AG: An acute infundibulopelvic angle predicts failure of flexible ureteroscopy for lower calyceal stones. J Urol 2000;163:339A.

3. Albala DM, Assimos DG, Clayman RV, Denstedtd JD, Grasso M, Gutierrez-Aceves J, et al: Lower pole I: a prospective randomized trial of extracorporeal shock wave lithotrispsy and percutaneous nephrostolithothomy for lower pole nephrolithiasis-initial results. J Urol 2001;166(6):2072-80.

4. El Nahas AR, Ibrahim HM, Youssef RF, Sheir KZ: Flexible ureterorenoscopy versus extracorporeal shock wave lithotripsy for treatment of lower pole stones of 10-20mm. BJU Int 2012;110(6):898-902.

5. Geavlete P, Multescu R, Geaviete B: Influence of pyelocaliceal anatomy on the success of flexible ureteroscopic approach. J Endour 2008;22(10):2235-9.

6. Jessen JP, Honeck P, Knoll T, Wendt-Nordahl G: Flexible ureteroreoscopy for lower pole stones: Influence of the collecting system's anatomy. J Endourol 2014;28(2):146-51.

7. 7) Sharma G, Jangid DK, Yadav SS, Mathur R, Tomar V: Retro-renal colon: role in percutaneous access. Urolithiasis 2015; 43(2):171-175.

Luciano A. Favorito, MD, PhD

Associated Professor of the Urogenital Unit from State University from Rio de Janeiro

Associated Editor of International Braz J Urol 